\title{
Prevalence and Antibiotic Sensitivity of Pseudomonas aeruginosa Isolated from CSOM in NMCH, Patna, India
}

\author{
Rajiv Ranjan Prasad ${ }^{1 *}$, Vijay Shree ${ }^{2}$, Rajesh Kumar ${ }^{1}$, Kalyani Kala ${ }^{1}$ and Prabhat Kumar ${ }^{1}$ \\ ${ }^{1}$ Department of Microbiology, NMCH, Patna, India \\ ${ }^{2}$ Department of Community Medicine, IGIMS, Patna, India \\ *Corresponding author
}

\section{A B S T R A C T}

\begin{tabular}{l} 
K e y w o r d s \\
Chronic \\
Suppurative \\
Otitis Media, \\
Ear Discharge, \\
Microbiology, \\
Sensitivity, \\
Pseudomonas \\
aeruginosa \\
\hline Article Info \\
\hline $\begin{array}{l}\text { Accepted: } \\
\text { 26 May } 2017 \\
\text { Available Online: } \\
\text { 10 June } 2017\end{array}$ \\
\hline
\end{tabular}

Keywords

Chronic

Ear Discharge,

Microbiology,

Sensitivity,

Article Info

Accepted:

Available Online:

10 June 2017
Chronic Suppurative Otitis Media (CSOM) is a common infectious chronic ear disease in India. The present study was aimed to identify bacterial isolates associated with CSOM and their Antibiogram in patients attending Microbiology department of Nalanda Medical College \& Hospital, Patna. Samples were taken from 150 patients (both male and female) in all age groups during the period of Dec 2015 to March 2017 suffering from CSOM and having active ear discharge. Total 103 patients were found to be culture positive from the 150 known case of CSOM. Their Gram staining, direct microscopy, Culture sensitivity, and Biochemical tests were carried out to identify the organisms and to know their sensitivity pattern. Drug susceptibility testing was conducted using a modified Kirby Bauer disk diffusion method. The most common causal organisms isolated were Pseudomonas aeruginosa 35(33.98\%) followed by Staphylococcus aureus 29 (28.15\%). The antimicrobial profile of the major isolates i.e. Pseudomonas aeruginosa and Staph. aureus revealed maximum sensitivity to Piperacillin / Tazobactum against $100 \%$ and 93.1\% isolates respectively. Pseudomonas aeruginosa is the most common isolate followed by Staphylococcus aureus. Both of these are sensitive to Piperacillin / Tazobactum. The study of microbial pattern and their antibiotic sensitivity determines the prevalent bacterial organisms causing CSOM in local area and to start empirical and more targeted treatment of otitis media and its complications for successful outcome, thus to prevent the emergence of resistant strains.

\section{Introduction}

Chronic suppurative otitis media (CSOM) is a prevailing and notorious infection in developing countries causing serious local damage and threatening complications. It is characterised by painless discharge from ears dating from months to years and is the single major cause of deafness in India. It is common amongst children of low socio economic strata (Mymen, 2005). The introduction of antibiotics has reduced the incidence of intra cranial complications in otitis media. Early and effective treatment based on the knowledge of causing microorganisms and their sensitivity results in good clinical recovery and prevents damage and complications. Pseudomonas aeruginosa was the most common pathogen among the cases of CSOM reported by several workers in India and abroad with an incidence ranging from $21 \%$ to $52.94 \%$ (Gulati et al., 1969; Brook et al., 1979; Ayyagiri et al., 1981; 
Maninder et al., 1985; Atanu et al., 1991). Hence, in this study an effort has been made to:

Identify the most common bacterial etiology of CSOM.

Determine the antibiogram of the Pseudomonas aeruginosa

\section{Materials and Methods}

This was a retrospective study conducted at Nalanda Medical College and Hospital, Patna from Dec 2015 to March 2017. Ear discharge were collected from them under strict aseptic precautions using two sterile cotton swabs with the assist of aural speculum and processed immediately in the microbiology laboratory.

The first swab was used for direct Gram stain and the second swab was cultured in nutrient agar, blood agar and MacConkey agar plates and incubated at $37^{\prime} \mathrm{C}$ for $24-48 \mathrm{hrs}$. The colonies of $P$. aeruginos $a$ were identified by colony morphology, pigment production, characteristic musty or earthy odour (Collee et al., 1996).

The identification was confirmed by motility and biochemical tests, which included fermentation of sugars, oxidation fermentation, indole production, nitrate reduction, oxidase, and catalase test.

Antimicrobial susceptibility testing was done by Kirby-Bauer's disc diffusion method, according to the guidelines of Clinical and Laboratory Standards Institute (CLSI) (Bailey and Scotts, 1990).

The following anti-microbials were usedTazobactum/Piperacillin (100 $\mathrm{mcg})$, Gentamicin (10 mcg), Amikacin $(30 \mathrm{mcg})$, Ciprofloxacin $(5 \mathrm{mcg})$, Ceftriaxone $(30 \mathrm{mcg})$,
Ceftazidime (30 mcg), Levofloxacin (5 mcg) and Imipenem (10 mcg) (Hi Media, Mumbai). $P$. aeruginosa ATCC 27853 was used as the control strain.

\section{Results and Discussion}

A total of 150 patients were selected for the study, Out of the 150 swabs, 103 showed growth giving an Isolation Rate of $68.66 \%$. A total of 150 bacterial isolates were studied from Dec 2015 to March 2017. The study included patients in the Age ranged from 6 month to 80 Years, with Peak age group being $11-30$ years was noted in 66 cases $(54.36 \%)$ (Table 1). The male and female distribution was $58.32 \%$ and $41.68 \%$ respectively.

Pseudomonas aeruginosa (33.98\%) was the most common bacterial agent found in chronic discharging ear, followed by Staphylococcus aureus (28.15\%), CONS (13.59\%), Klebsiella $(7.76 \%)$ and E. coli (4.85\%) Antibiotic susceptibility was tested by Minimum inhibitory concentration (MIC) method using Mueller-Hinton agar. Sensitivity pattern of

Pseudomonas aeruginosa showed that Tazobactum/Piperacillin was active against $100 \%$ of isolates followed by Imipenem 91.4\%, Levofloxacin 85\%, Ceftazidime, Amikacin and Ciprofloxacin (Table 2).

Knowledge of local bacteriological profile is important for empirical of CSOM. Untreated cases of CSOM may result in a broad range of intracranial and extra-cranial complications. In the present study most common age group affected was 11-30 years (Table 1). This finding is similar to other studies (Wikler, 2006; Shyamala et al., 2012; Wariso et al., 2006). In the study males were more affected than females. Some studies have found male preponderance (Prakash et al., 2013) while others have found female preponderance 
(Teele et al., 1989). This difference might be due to local demographic characteristics. Microbial growth was seen in $68.66 \%$ of the cases, $31.34 \%$ cases were sterile. Other studies have reported sterile cases ranging between 3\% to 16.9\% (Ahmed et al., 1999; Loy et al., 2002; Chakraborty et al., 2005).

Pseudomonas aeruginosa was the most common organism isolated followed by Staphylococcus aureus.
Other studies have reported varying prevalence between these two organisms. Some studies have reported Staphylococcus aureus as the most common organism (Vijaya, 2000; Kumar et al., 2008), other studies have reported Pseudomonas aeruginosa as the most common organism (Malkappa et al., 2012; Gaur et al., 2013; Taneja et al., 2009). This finding suggests that microbial pattern differs with time and geographical location.

Table.1 Age ranged from 6 month to 80 Years, with Peak age group being 11-30 years

\begin{tabular}{|c|c|c|}
\hline S. No. & Age in Year & No of positive cases \\
\hline 1. & $<1$ & 0 \\
\hline 2. & $1-10$ & 12 \\
\hline 3. & $11-20$ & 36 \\
\hline 4. & $21-30$ & 30 \\
\hline 5. & $31-40$ & 11 \\
\hline 6. & $41-50$ & 7 \\
\hline 7. & $51-60$ & 4 \\
\hline 8. & $61-70$ & 3 \\
\hline 9. & $71-80$ & 0 \\
\hline
\end{tabular}

Table.2 Sensitivity pattern of organism isolated from CSOM Patients

\begin{tabular}{|l|c|c|c|c|c|c|c|c|c|}
\hline $\begin{array}{l}\text { Type of } \\
\text { organism }\end{array}$ & $\begin{array}{l}\text { Total No. } \\
(\boldsymbol{\%})\end{array}$ & $\begin{array}{l}\text { AK } \\
(\boldsymbol{\%})\end{array}$ & $\begin{array}{l}\text { CAZ } \\
(\boldsymbol{\%})\end{array}$ & $\begin{array}{l}\text { CT } \\
(\boldsymbol{\%})\end{array}$ & $\begin{array}{l}\text { CP } \\
(\boldsymbol{\%})\end{array}$ & $\begin{array}{l}\text { GM } \\
(\boldsymbol{\%})\end{array}$ & $\begin{array}{l}\text { IM } \\
(\boldsymbol{\%})\end{array}$ & $\begin{array}{l}\text { LEV } \\
(\boldsymbol{\%})\end{array}$ & $\begin{array}{l}\text { TZ } \\
(\boldsymbol{\%})\end{array}$ \\
\hline P. aeruginosa & 35 & 23 & 29 & 18 & 25 & 16 & 32 & 31 & 35 \\
& $(33.9)$ & $(65.7)$ & $(82.8)$ & $(51.4)$ & $(71.4)$ & $(45.7)$ & $(91.4)$ & $(88.5)$ & $(100)$ \\
\hline S. aureus & 29 & 17 & 26 & 24 & 22 & 18 & 22 & 24 & 27 \\
& $(28.1)$ & $(58.5)$ & $(89.6)$ & $(82.7)$ & $(75.8)$ & $(62.1)$ & $(75.8)$ & $(82.7)$ & $(93.1)$ \\
\hline CONS & 14 & 7 & 2 & 2 & 3 & 0 & 2 & 2 & 3 \\
& $(13.5)$ & $(50)$ & $(14.2)$ & $(14.2)$ & $(21.4)$ & & $(14.2)$ & $(14.2)$ & $(21.4)$ \\
\hline Proteus species & 4 & 3 & 3 & 3 & 2 & 0 & 3 & 2 & 3 \\
& $(3.8)$ & $(75)$ & $(75)$ & $(75)$ & $(50)$ & & $(75)$ & $(50)$ & $(75)$ \\
\hline E.coli & 5 & 4 & 3 & 3 & 1 & 3 & 4 & 4 & 3 \\
& $(4.8)$ & $(80)$ & $(60)$ & $(60)$ & $(20)$ & $(60)$ & $(80)$ & $(80)$ & $(60)$ \\
\hline Strep. & 8 & 7 & 4 & 4 & 7 & 4 & 4 & 7 & 7 \\
pneumoniae & $(7.7)$ & $(87.5)$ & $(50)$ & $(50)$ & $(87.5)$ & $(50)$ & $(50)$ & $(87.5)$ & $(87.5)$ \\
\hline K. pneumoniae & 8 & 4 & 2 & 6 & 2 & 2 & 4 & 7 & 6 \\
& $(7.7)$ & $(50)$ & $(25)$ & $(75)$ & $(25)$ & $(25)$ & $(50)$ & $(87.5)$ & $(75)$ \\
\hline Total & $103(100)$ & & & & & & & & \\
\hline
\end{tabular}

AK-Amikacin, CAZ-Ceftazidime, CT-Ceftriaxone, CP-Ciprofloxacin, GM-Gentamicin, IM-Imipenem, LEVLevofloxacin, TZ-Tazobactum/Piperacillin 
$P$. aeruginosa showed highest resistance to Gentamicin and Ceftriaxone and least resistance with Tazobactum/Piperacillin and Imipenem (Table 2). Other authors have reported sensitivity of $45 \%$ to $87 \%$ with Aminiglycosides (Indudharan et al., 1999; Kumar et al., 2012). Sensitivity to Quinolone antibiotic was $71.4 \%$ with Ciprofloxacin and $88.5 \%$ with Levofloxacin. Other studies have reported sensitivity to Quinolones ranging from $61 \%$ to $90 \%$. Sensitivity to third generation Cephalosporins ranged from $50 \%$ to $70 \%$. This finding is in agreement with other studies (Ahmed et al., 1999; Loy et al., 2002; Chakraborty et al., 2005). Among all the organisms, Pseudomonas aeruginosa is prone to cause a problem in therapeutic control of CSOM (Taneja et al., 2009). Staphylococcus aureus has inherent trait of resistance. In the present era of newer antibiotics, the emergence of antibiotic resistance is becoming more common. Another factor responsible for resistance is patient non-compliance, as soon as symptoms subside, many patients stop taking antibiotics before completion of therapy.

Pseudomonas aeruginosa was the most common pathogen followed by Staphylococcus aureus isolated from CSOM. Piperacillin/Tazobactum was found to be the most suitable antibiotic followed by Imipenem and Levofloxacin for Pseudomonas aeruginosa. The resistance against ceftriaxone and Gentamicin was found to be very high.

The important factor that is responsible for resistance is inappropriate duration, dose and selection of antibiotics. It is essential to use antibiotics in proper way to prevent emergence and spread of resistant pathogens.

\section{Acknowledgement}

We thank the faculty and staff of Microbiology Deptt, NMCH, Patna, who helped us to carry out our study.

\section{References}

Ahmed, A., Usman, J., Hashim, R. 1999. Isolates from chronic suppurative otitis media and their antimicrobical sensitivity. Pak. Armed Forces Med. J., 49: 82-5.

Atanu Nandy, P.S., Mllya, K., Sivarajan. 1991. Indian J. Otolaryngol. Head \& Neck Surgery, 43(3): 136.

Ayyagiri, A., Pancholi, V.K. Pandhi, et al. 1981. Indian J. Med. Res., 73: 860.

Bailey and Scotts. 1990. Non fermentative gram negative Bacilli and coccobacilli. Diagnostic microbiology. 12 th ed. St. Louis, Missouri (US): Mosby Elsevier; 386-407.

Brook, I., S.M. Finegold. 1979. JAMA, 241(5): 487.

Chakraborty, A., Bhattacharjee, A., Purkaystha, P. 2005. Microbiological profile of chronicsuppurative otitis media: Its significance inNorth-East India. Indian J. Otol., 11: 39-44.

Collee, J.G., Miles, R.S., Watt, B. 1996. Tests for identification of bacteria. In: Collee JG, Fraser AG, Marmion BP, Simmons A, Eds. Mackie \& McCartney Practical Medical Microbiology, 14th ed. New York \& London: Churchill Livingstone, 131-149.

Gaur, R.S., Mathew, J., Varghese, A.M., Mathew, G.A., Chandrasekharan, R., Anandan, S. 2013. Microbiological pattern of ear swabs inchronically discharging ears in a Tertiary Care hospital in India. Indian J Otol., 19: 514.

Goyal, R., Aher, A., De, S., Kumar, A. 2009. Chronic suppurative otitismedia - A Clinico- Microbiological study. Indian J. Otol., 15: 18-22.

Gulati, J., P.L. Tandon, Waryan Singh. 1969. Indian J. Otolaryngol. Head \& Neck Surgery, 21(4): 198. 
Indudharan, R., Haq, J.A., Aiyar, S. 1999. Antibioticsin chronic suppurative otitis media: a bacteriologic study. Ann. Otol. Rhinol. Laryngol., 108: 440-5.

Kumar, S., Sharma, R., Saxena, A., Pandey, A., Gautam, P., Taneja, V. 2012. Bacterial flora of infected unsafe CSOM. Indian J. Otol., 18: 208-11.

Kumar, S., Sharma, R., Saxena, A.K., Pandey, A., Gautam, P., Jain, R. 2008. A study of bacterial flora and sensitivity to antibiotics in cases of CSOM TTD in western UP. Indian J. Otol., 14: 20-4.

Loy, A.H., Tan, A.L., Lu, P.K. 2002. Microbiology of chronic suppurative otitis media in Singapore. Singapore Med. J., 43: 296-9.

Madana, J., Yolmo, D., Kalaiarasi, R., Gopalakrishnan, S., Sujata, S. 2011. Microbiological profile with antibiotic sensitivity pattern of cholesteatomatous chronic suppurative otitis media among children. Int. J. Pedia. Otorhinolaryngol., 75: 1104-8.

Malkappa, S..K, Kondapaneni, S., Surpam, R.B., Chakraverti, T.K. Study of aerobic bacterial isolates and their antibiotic susceptibility pattern in chronic suppurative otitis media. Indian J. Otol., 18: 136-9.

Maninder Pal Singh, Harminder Prabhakar, Satya Arora. 1985. India. J. Med. Microbiol., 3: 177.

Mymen Singh. 2005. Med. J., 14(2): 152-5.

Prakash, R., Juyal, D., Negi, V., Pal, S., Adekhandi, S., Sharma, M., et al. 2013. Microbiology of chronic suppurative otitis media in a tertiary care setup of uttarakhand state, India. North Am. J. Med. Sci., 5: 282-7.

Rao, R., C.S. Baskaran. 1984. Indian J. Pathol. Microl., 27(4): 341.

Shyamala, R., Reddy, P.S. 2012. The study of bacteriological agents of chronic suppurativeotitis media: Aerobic culture and evaluation. J. Microbiol. Biotech. Res., 2: 152-62.

Tahir, M., Jawaid, A., Abdullah, A., Najam, M.A. 2012. Bacterial culture and sensitivity in active chronic otitis media: 500 cases in combined military hospital Rawalpindi. Pak. J. Otolaryngol., 28: 56-8.

Taneja, M., Taneja, M.K. 2009. CSOM a bacteriological study. Indian J. Otol., 15: 3-7.

Teele, D.W., Klein, J.O., Rosner, B. 1989. Greater Boston Otitis Media Study Group.Epidemiology of otitis media during the first seven years of life in children in greater Boston: A prospective, cohort study. J. Infect. Dis., 160: 83-94.

Vijaya, D. 2000. Aerobes, anaerobes, and fungi inchronic suppurative otitis media. Indian J. Otol., 6: 55-8.

Wariso, B.A., Ibe, S.N. 2006. Bacteriology of chronic discharging ears in Port Harcourt, Nigeria. West Afr. J. Med., 25: 219-22.

Wikler, M.A. 2006. Performance standards for antimicrobial susceptibility testing: Sixteenth informational supplement Clinical and Laboratory Standards Institute.

\section{How to cite this article:}

Rajiv Ranjan Prasad, Vijay Shree, Rajesh Kumar, Kalyani Kala and Prabhat Kumar. 2017. Prevalence and Antibiotic Sensitivity of Pseudomonas aeruginosa Isolated from CSOM in NMCH, Patna. Int.J.Curr.Microbiol.App.Sci. 6(6): 2912-2916. doi: https://doi.org/10.20546/ijcmas.2017.606.345 